\title{
Acute and Long Term Effects of a Nutraceutical Combination on Lipid Profile, Glucose Metabolism and Vascular Function in Patients with Dyslipidaemia with and Without Cigarette Smoking
}

\author{
Davide Grassi ${ }^{1}\left[\right.$ [ $\cdot$ Stefano Necozione ${ }^{1} \cdot$ Giovambattista Desideri $^{1} \cdot$ Stefano Abballe $^{1} \cdot$ Francesca Mai $^{1}$. \\ Martina De Feo ${ }^{1}$. Augusto Carducci ${ }^{1}$. Claudio Ferri ${ }^{1}$
}

Received: 10 June 2021 / Accepted: 25 July 2021 / Published online: 13 September 2021

(c) The Author(s) 2021

\begin{abstract}
Introduction Lifestyle changes present a fundamental role in cardiovascular prevention. Nutraceuticals also supplementing diet could help in controlling the cardiometabolic risk.

Aim (1) to evaluate acute effects of a combination of nutraceuticals (cNUT) on vascular function, BP, metabolism in dyslipidaemic patients before and after smoking; (2) to evaluate 12 weeks effects of the cNUT on lipid profile, insulin resistance and vascular function in patients with hypercholesterolemia not on statins.

Methods After $14 \mathrm{~d}$ run-in period, 33 patients assumed a cNUT [patented formula containing: berberine (531.25 mg), red yeast rice powder (220 mg, $3.3 \mathrm{mg}$ monacolin K) and leaf extract of Morus alba (200 mg) (LopiGLIK ${ }^{\circledR}$, Akademy Pharma)]. To evaluate acute effects, cNUT or cNUT + smoking (in smoking subjects) on the morning of the first day of the study and then 26 patients prolonged 12 weeks effects.

Results In non smokers, cNUT improved FMD ( $p=0.041$ for treatment). In smokers, FMD decreased after smoking, this was counteracted by intake of cNUT. In smokers, DBP increased after smoking a cigarette $(p=0.042$ for treatment), counteracted by the cNUT intake. In non smokers, thermogenesis was increased after cNUT administration $(\mathrm{p}<0.0001$ for treatment). After 12 weeks of cNUT, FMD significantly increased $(\mathrm{p}<0.05)$ and SBP $(\mathrm{p}=0.04)$, total cholesterol and LDL cholesterol $(\mathrm{p}=0.03)$ decreased.

Conclusions Our study suggests benefits of cNUT on cardiovascular prevention in hypercolesterolemic patients, non statin treated, that goes beyond the cholesterol and insulin resistance reduction protecting the subject from negative effects induced by smoking too.
\end{abstract}

Keywords Nutraceuticals $\cdot$ Hypercholesterolemia $\cdot$ Smoking $\cdot$ Flavonoids $\cdot$ Cardiovascular risk

\section{Introduction}

Cardiovascular risk factors are associated with an increased risk of atherosclerotic disease and cardiovascular events [1]. The control of cardiovascular risk therefore remains a specific target in the prevention and management of atherosclerotic disease and a great challenge for cardiovascular prevention in Western countries [2]. Recent studies have

Davide Grassi

davide.grassi@univaq.it

1 Department of Life, Health and Environmental Sciences, University of L'Aquila, Viale S Salvatore, Delta 6 Medicina, 67100 L'Aquila, Coppito, Italy shown how the early assessment of vascular damage and in particular of endothelial dysfunction play a dominant role in the prognosis of the population with high cardiovascular risk [3]. In fact, endothelial dysfunction seems to play an important role in the pathogenesis of cardiovascular diseases [4]. This hypothesis is supported by prospective studies showing that endothelial dysfunction is a predictor of future cardiovascular events [5]. Endothelial dysfunction is a crucial event of atherogenesis, which occurs early because of exposure to common cardiovascular risk factors [6]. In fact, arterial hypertension, dyslipidaemia, type 2 diabetes, cigarette smoking can induce oxidative stress [7, 8], inflammation [9], platelet hyperaggregability and inactivation of nitric oxide (NO) with alteration of endothelial function [10]. 
A pivotal role in cardiovascular prevention is represented by dietary and lifestyle changes (limitation of caloric intake, limitation of fats in particular of saturated and trans fats, avoid foods or drinks with a high glycaemic index, regularly practice physical exercises, etc.) $[6,11]$ often difficult to control due to the patient's poor adherence to the recommended modifications [12]. Additionally, increasing evidence support the fundamental role of nutraceuticals in counteracting cardiovascular risk factors as in case of hypercholesterolemia and hypertension [13]. Further, flavonoids have been reported to improve insulin resistance and endothelial function and decrease blood pressure also by increasing the bioavailability of $\mathrm{NO}$ and reducing the formation of reactive oxygen and nitrogen species [14].

In accordance with the clinical evidence, experimental studies have shown that dietary supplementation with cocoa procyanidins was able to prevent, in a dose-dependent manner, the development of hyperglycaemia in obese mice [15]. However, the above data have not yet had definitive confirmation and part of the insufficient information deriving from human intervention studies is often attributable to inaccuracies in the study design and the different dosage of nutraceuticals used [16]. Some natural bioactive nutraceuticals (berberine, white mulberry and monacolin) have shown in various preclinical and clinical studies to improve lipid structure, fasting glycemia, insulin resistance, and some anthropometric parameters related to overweight to varying degrees [17].

In this context, therefore, the intake of natural substances to be taken with the diet in the form of food supplements could help in controlling the cardiometabolic risk [18]. A combined nutraceutical that could allow in single administration to improve glyco-lipid metabolism and other parameters related to overweight when associated with correct eating habits and regular physical activity, could constitute a fundamental tool to decrease the exposure to important risk factors and increasing patient compliance with healthy lifestyles [19-21].

Moreover, it is also possible to combine nutraceuticals with different lipid-lowering actions. Particularly, the association between nutraceuticals and lifestyle changes could be considered a valid alternative tool to pharmacological treatment in primary prevention patients with low to moderate cardiovascular risk and in some statin intolerant patients. Furthermore, molecules with different mechanisms of action can be associated to obtain a synergistic effect, acting on the intestinal absorption of lipids and/or their excretion.

Therefore, aim of the study was to evaluate: the acute effects of a cNUT (LopiGLIK ${ }^{\circledR}$ ) on vascular function (endothelial function and arterial stiffness) in dyslipidaemic patients before and after smoking (in smokers). Furthermore we aimed to evaluate 12 week effects of prolonged intake ( 1 tablet per day) of the cNUT on lipid profile, insulin resistance and vascular function in patients with hypercholesterolemia not on statins.

\section{Methods}

\subsection{Study Design}

We conducted a randomized single-blind study to evaluate the acute effects of a cNUT (LopiGLIK ${ }^{\circledR}$ ) on vascular function, BP and metabolism before and after smoking in patients with hypercholesterolemia not on statins.

The study population included consecutive adult patients (age $\geq 18$ e $\leq 75$ ) referring to our ambulatory of Nutrition, Metabolism and Cardiovascular prevention with hypercholesterolemia. According to the inclusion/exclusion criteria (Table 1), we enrolled patients not requiring statins or reporting statin intolerance. The study protocol was approved by local Ethics Committee. All participants gave their written informed consent.

After a 2-week run-in phase, during which patients were suggested to follow a specific nutritional pattern based on Mediterranean diet (fruits, vegetables, intake of fish, legumes, unrefined whole grains, low fat dairy products olive oil, unrefined whole grains and a moderate intake of alcohol), participants responding to the inclusion/exclusion criteria (Tables 1, 2) were assigned to assume LopiGLIK ${ }^{\circledR}$ containing Berberine $(531 \mathrm{mg})$, Red yeast rice powder (a.3 $\mathrm{mg}$ Monacolin K) and Morus alba (200 mg) combination.

To evaluate acute effects, on the morning of the study visit, the volunteers arrived in a fasting state and after clinical visit with measurement of anthropometric parameters they take the cNUT product. Vascular measures were performed before $(\mathrm{t}=0)$ and 1,2 , and $3 \mathrm{~h}$ after consumption of the test product in a supine position in a quiet, temperaturecontrolled $\left(22-24{ }^{\circ} \mathrm{C}\right)$ room by trained, certified staff who were blind to the study protocol. In smokers, this procedure was repeated in 2 days, after smoking a cigarette (after $1 \mathrm{~h}$, $2 \mathrm{~h}$ and $3 \mathrm{~h}$ ) and after smoking $+\mathrm{cNUT}$ product intake (after $1 \mathrm{~h}, 2 \mathrm{~h}$ and $3 \mathrm{~h}$ ). Then, after the acute phase smokers and non smokers volunteers continued to assume LopiGLIK ${ }^{\circledR}$ ( 1 tab per day) for 12 weeks. Before and after this intervention period the lipid profile, the glyco-insulinemic pattern and HOMA-index and endothelial function were measured.

\subsubsection{Endothelial Function}

In non smokers participants, FMD of the brachial artery was measured before (baseline, $\mathrm{t}=0$ ) and 1,2 , and $3 \mathrm{~h}$ after the cNUT product. While in smokers volunteers FMD was evaluated before (baseline, $\mathrm{t}=0$ ) and 1,2 , and $3 \mathrm{~h}$ after smoking and 1, 2, and $3 \mathrm{~h}$ after smoking + intake of cNUT product. FMD of the brachial artery was assessed 
Table 1

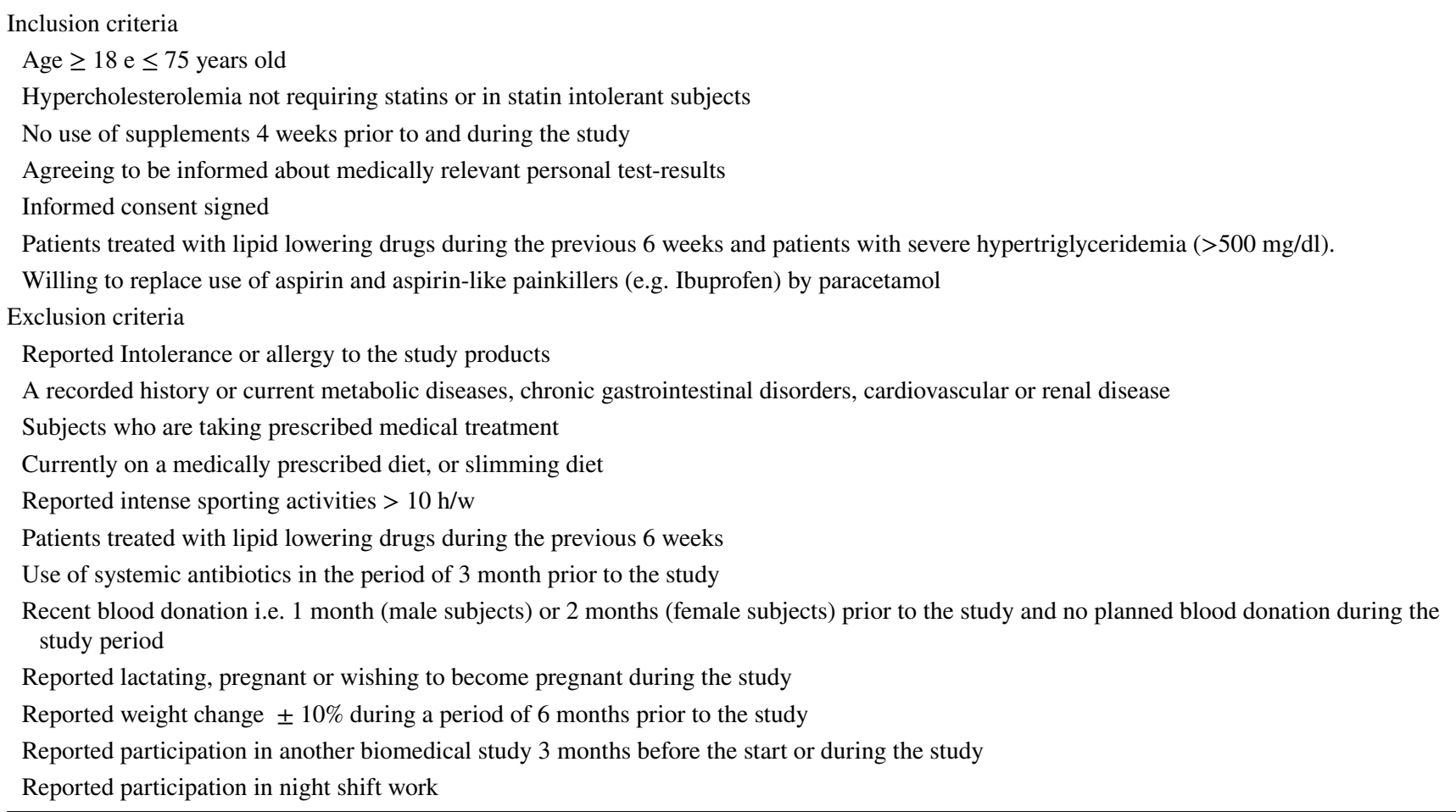

Table 2 Basal clinical characteristics of the study population

\begin{tabular}{ll}
\hline Number of patients & 33 \\
Age (years) & $45 \pm 13$ \\
Gender (male/female) & $17 / 16$ \\
Weight $(\mathrm{Kg})$ & $79.9 \pm 16.3$ \\
BMI & $27.2 \pm 4.2$ \\
SBP (mmHg) & $127 \pm 10.5$ \\
DBP (mmHg) & $78.4 \pm 7.5$ \\
HR (b/min) & $67 \pm 13$ \\
\hline
\end{tabular}

Data are given as mean \pm SD

after 15 min at rest. FMD was always determined by the same physician, who was blinded to the study design and objectives. FMD of the brachial artery of the dominant arm was measured by ultrasonography (General Electric). The transducer was held at the same point throughout the scan by a stereotactic clamp. The arterial diameter was measured at approximately $5-10 \mathrm{~cm}$ above the elbow. Endothelium-dependent vasodilation was considered the maximal dilation of the brachial artery induced by the increased flow using the FMD Studio system (QUIPU, Pisa, Italy) as previously described [22, 23].

\subsubsection{Blood Pressure Measurements}

Office BP measurements were recorded by a validated oscillometric device with appropriately sized cuffs (Omron 705 CP; Omron Matsusaka Co. Ltd., Matsusaka-City, Japan) on the dominant upper arm. For this purpose, patients rested 15 min in supine position. Then, the first BP measurement was discarded and the subsequent three consecutive BP readings, taken at $5 \mathrm{~min}$ intervals, were recorded. The average of these latter measures was considered for statistical analysis.

\subsection{Thermogenesis and Energy Expenditure}

The SenseWear Armband (Bodymedia, Pittsburg, Pennsylvania, USA) is a triaxial accelerometer and sensors for skin temperature, heat flux, and galvanic skin responses. The patterns of signals from these sensors are combined to determine the type and intensity of activity. Proprietary algorithms including individual characteristics (age, sex, weight, height) are used to estimate energy expenditure and skin temperature each minute. The monitor was attached with the elastic strap around the non-dominant arm, and collected data were processed in both software 6.1.

\subsubsection{Haematochemistry and Blood Lipids}

In all individuals, a routine hematochemical check was performed by standard methods at baseline and after long-term 
active treatment phase. Fasting plasma glucose and insulin, serum total cholesterol, high-density lipoprotein (HDL) cholesterol, low-density lipoprotein (LDL) cholesterol, and triglyceride levels were assessed in the clinical chemistry laboratory using routine procedures. Plasma glucose and insulin values were used to calculate the index of insulin resistance, the homeostasis model assessment of insulin resistance (HOMA-IR).

\subsection{Statistical Analysis}

Data analysis was performed using the SAS software (SAS Institute, Cary, NC, USA, version 9.4). Descriptive analysis consisting of distribution statistics (number of available observations, mean and standard deviations) were presented for continuous data.

The Shapiro-Wilk test was used to test the normality of variables distribution.

The analysis of differences in variables, in the overall sample of smokers and non-smokers between baseline and 12 weeks, was carried out with Student's t-test for paired data.

A linear-mixed models with Proc Mixed Procedure were used for repeated measures analysis of data in smokers before and after smoking (smoking considered as treatment).

Repeated measures analysis of variance with Proc ANOVA was used to evaluate differences in time in the values of variables in smokers and non-smokers. Post-hoc comparisons were performed with the Bonferroni test, using a downward adjustment of the $\alpha$ error to compensate for multiple comparisons.

Statistical power was based on results obtained in similar studies with polyphenols on FMD (i.e. FMD increased by $1.9 \%$ at a SD of $1.6 \%$ after cocoa polyphenol consumption). Therefore, a total sample number of 20 subjects was considered sufficient to demonstrate statistically significant (two-sided, alpha $=0.05$ and power $=0.80$ ) an average difference $=1$ and $\mathrm{SD}=1$ in the values of FMD between baseline ad 12 weeks. Statistical power was calculated using G*Power Version 3.1.9.7.

\section{Results}

We enrolled 19 non smoking (mean age $50 \pm 11.6$ years) and 14 smoking volunteers (mean age $38 \pm 12$ years) responding to the inclusion/exclusion criteria (Table 1) were evaluated for acute effects. Clinical characteristics of the study population are reported in Table 2.
Acute effects on FMD in non smokers

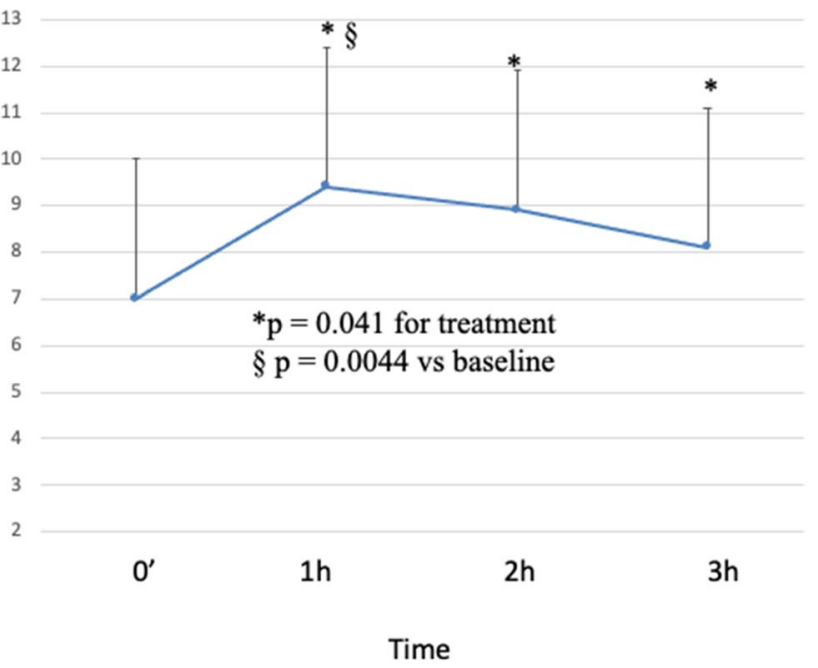

Fig. 1 Acute effects of a cNUT (LopiGLIK ${ }^{\circledR}$ ) on endotheliumdependent flow-mediated dilation in 19 non smoker patients with hypercholesterolemia. Data are means \pm SD. Data points with different superscripts are significantly different. *Different from baseline. Differences are considered significant when $p<0.05$.

Then 26 volunteers prolonged the intervention study to 12 weeks. 7 patients refused to continue with the long-term study for personal reasons.

\subsection{Acute and Long-Term Effects}

\subsubsection{FMD}

In non smokers, FMD significantly acutely increased from $7.0 \pm 3.0 \%$ to $9.4 \pm 3.9 \%, 8.9 \pm 3.3 \%$ and $8.1 \pm 3.6 \%$ after 1,2 and $3 \mathrm{~h}$ from intake of the cNUT, respectively (Fig. 1). Respect to baseline values, cNUT significantly improved FMD endothelial function ( $\mathrm{p}=0.041$ for treatment).

In smokers, FMD decreased from $5.2 \pm 2.5 \%$ to $4.7 \pm 2.4 \%, 4.9 \pm 3.9 \%$ and $3.7 \pm 1.1 \% 1,2$ and $3 \mathrm{~h}$ after smoking a cigarette, respectively. Always in smokers, when smoking a cigarette was preceded by intake of cNUT, FMD did not decrease and changed from $5.0 \pm 2.1 \%$ to $5.1 \pm 1.8 \%$, $5.2 \pm 2.4 \%$ and $4.4 \pm 2.8 \%$ (Fig. 2).

After 12 weeks of intervention, FMD significantly increased from $6.32 \pm 2.5 \%$ to $7.6 \pm 1.9 \%(\mathrm{p}<0.05)$ (Fig. 3).

\subsubsection{Blood Pressure}

In non smokers, SBP/DBP did not acutely change after cNUT administration. 


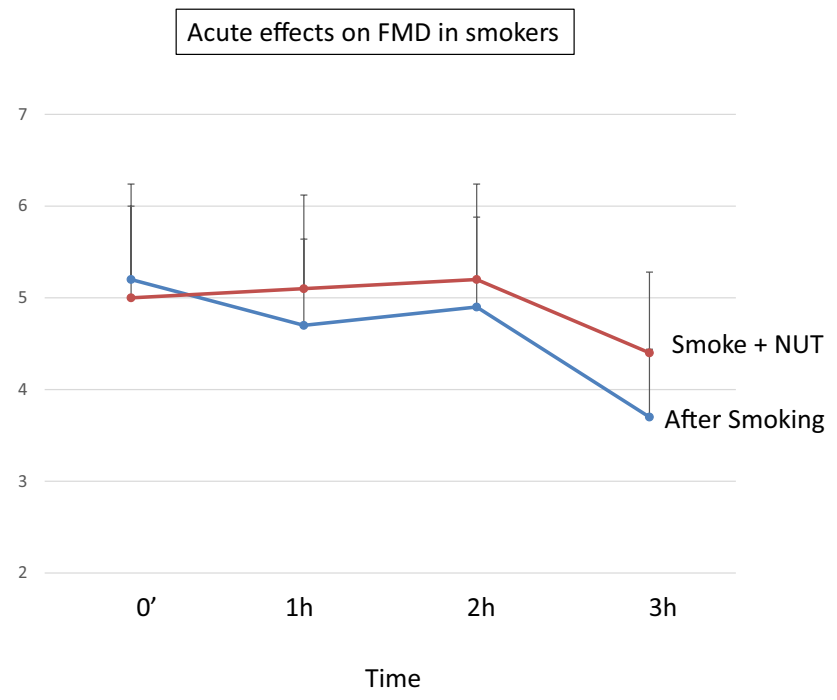

Fig. 2 Acute effects of smoking with and without intake of cNUT $\left(\right.$ LopiGLIK $\left.^{\circledR}\right)$ on endothelium-dependent flow-mediated dilation in 14 smoker patients with hypercholesterolemia. Data are means \pm SD. Differences are considered significant when $p<0.05$

12 wks NUT combination effects on FMD

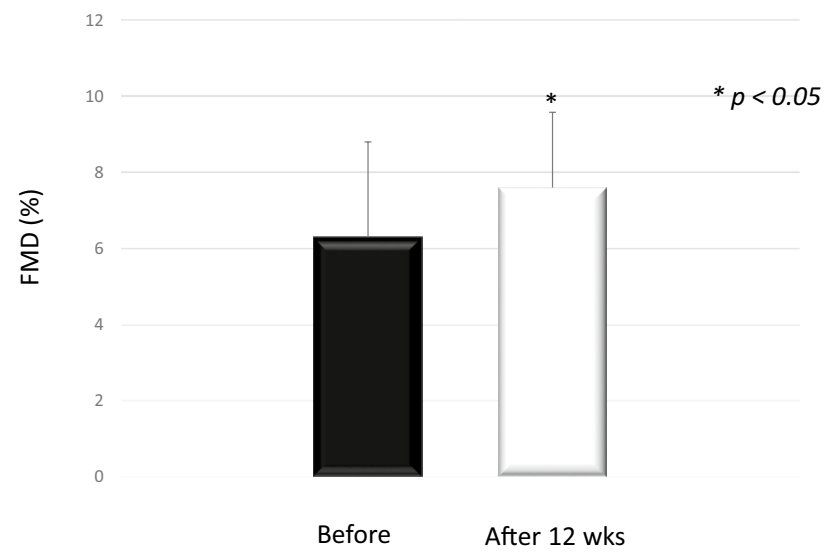

Fig. 3 Effects of 12 weeks consuming cNUT (LopiGLIK ${ }^{\circledR}$ ) on endothelium-dependent flow-mediated dilation in 26 smoker and no smoker patients with hypercholesterolemia. Data are means $\pm \mathrm{SD}$, $*$ Different from baseline. Differences are considered significant when $p<0.05$

In smokers, SBP did not change while DBP significantly acutely increased from $78.4 \pm 9.0 \mathrm{mmHg}$ to $83.9 \pm 10.4 \mathrm{mmHg}, 81.9 \pm 10.3 \mathrm{mmHg}$ and $81.1 \pm 7.5 \mathrm{mmHg}$ after 1,2 and $3 \mathrm{~h}$ after smoking a cigarette, respectively ( $\mathrm{p}=0.042$ for treatment). Always in smokers, when smoking a cigarette was preceded by intake of cNUT, SBP/DBP did not change.

After $12 \mathrm{wks}$ of intervention, SBP significantly decreased $(\mathrm{SBP} 131.6 \pm 11.0 \mathrm{mmHg}$ to
$125.2 \pm 11.1 \mathrm{mmHg}, \mathrm{p}=0.04)$; while DBP decreased but not significantly $(79.4 \pm 7.7 \mathrm{mmHg}$ to $78.3 \pm 8.5 \mathrm{mmHg}$; n.s.).

\subsection{Thermogenesis and Energy Expenditure}

In non smokers, thermogenesis was significantly increased after cNUT administration (Fig. 4A). Similarly but not significantly, the energy expenditure increased from $0.96 \pm 0.15$ METs to $0.99 \pm 0.16$ METs, $0.98 \pm 0.11$ METs and $0.96 \pm 0.13$ METs after 1,2 and $3 \mathrm{~h}$ from intake of the NUT combination, respectively (Figure 4B). In smokers, thermogenesis and energy expenditure increased but not significantly (Body surface temperature/energy expenditure: from $30.6 \pm 1.7{ }^{\circ} \mathrm{C} / 1.0 \pm 0.21$ METs to $31.3 \pm 1.1{ }^{\circ} \mathrm{C} / 1.1 \pm 0.16 \mathrm{METs}, 31.2 \pm 1.5{ }^{\circ} \mathrm{C} / 0.9 \pm 0.09$ METs and $31.9 \pm 0.9^{\circ} \mathrm{C} / 0.9 \pm 0.11$ METs 1,2 and $3 \mathrm{~h}$ after smoking a cigarette, respectively, n.s.). On the contrary, when smoking cigarette was preceded by intake of cNUT, body surface temperature significantly increased and energy expenditure raised from baseline after 1,2 , and $3 \mathrm{~h}$ after (Fig. 5A, B, respectively).

\subsubsection{Lipid, Glucose and Insulin Metabolism}

Respect to baseline values, total cholesterol and LDL cholesterol significantly decreased after 12 wks intervention with cNUT (Fig. 6A, B, respectively), while HDL cholesterol and triglycerides did not change. Insulin-resistance as well BMI and waist circumference decreased although not significantly (HOMA-index: from $1.92 \pm 1.2$ to $1.48 \pm 1.0$, BMI $27.2 \pm 4.0$ to $25.7 \pm 7.0 \mathrm{~kg} / \mathrm{m}^{2}$ and WC: $94.2 \pm 13.3$ to $87.0 \pm 22.2 \mathrm{~cm}$; n.s.).

The cNUT was well tolerated with no changes in ALT, AST and CPK.

\section{Discussion}

In our study we observed for the first time that a cNUT can acutely improve endothelial function, BP, thermogenesis and energy expenditure also suggesting counteracting effects on these parameters altered by smoking. Further, we also confirmed that $12 \mathrm{wks}$ of treatment with a cNUT approved by ESC/EAS guidelines for the management of dyslipidaemias was also able to improve the lipid profile in patients with hypercholesterolemia not requiring statins or statin intolerant [23]. According to this, potential additional effects to the well known effects related to Monakolin $\mathrm{k}$ and Berberine on plasma cholesterol and glucose metabolism [17, 20, 24], was also represented from the fundamental effect suggested by the action of Morus alba. Indeed, the Morus species is considered a very rich source 


\section{Acute effects of NUT on thermogenesis and energy expenditure in non smokers}

A

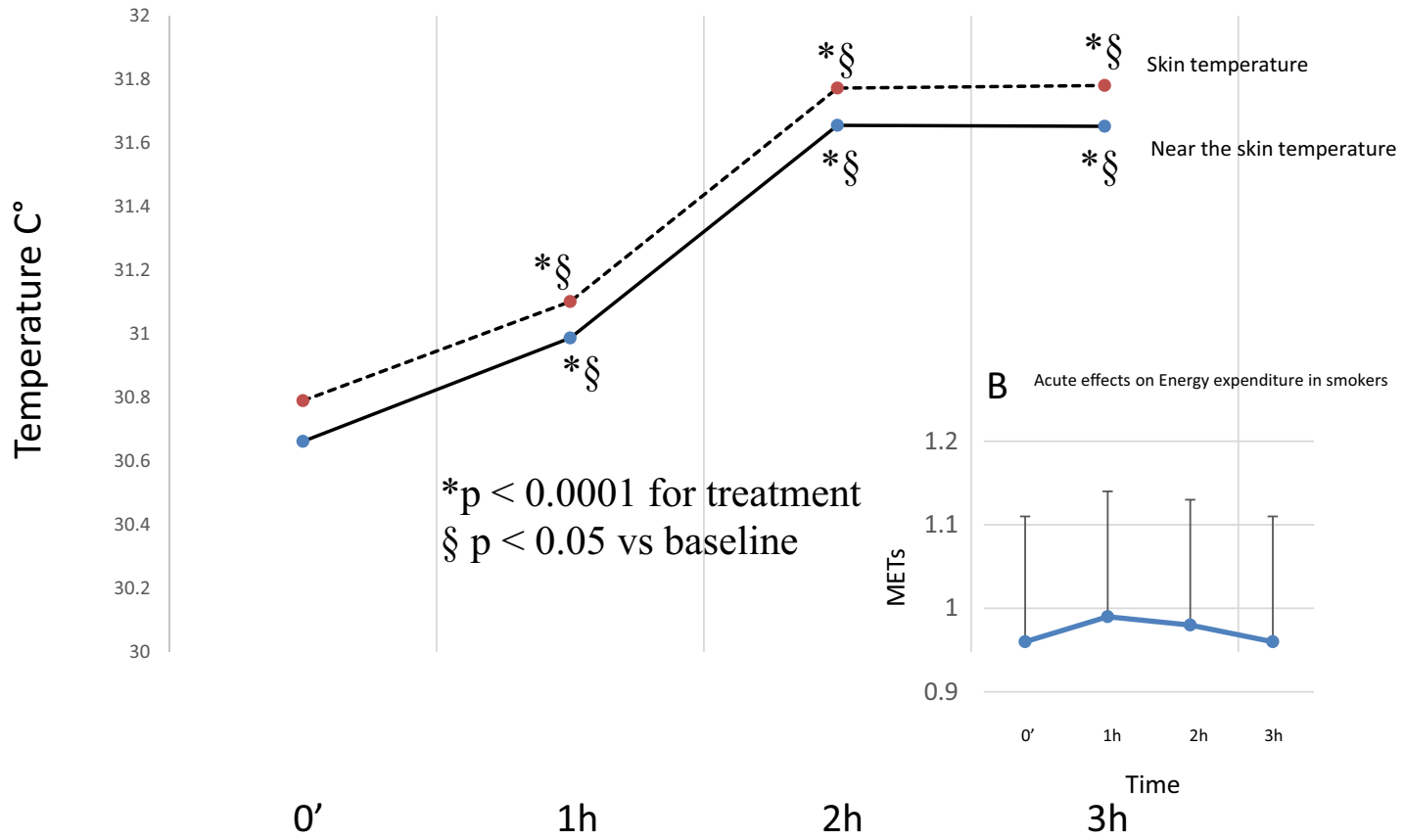

Time

Fig. 4 Acute effects of a cNUT (LopiGLIK ${ }^{\circledR}$ ) on thermogenesis (A) and energy expenditure (B) in 19 non smoker patients with hypercholesterolemia. Data are means \pm SD. Data points with different super- scripts are significantly different. *Different from baseline. Differences are considered significant when $\mathrm{p}<0.05$

A Acute effects on Thermogenesis in smokers

B Acute effects on Energy expenditure in smokers

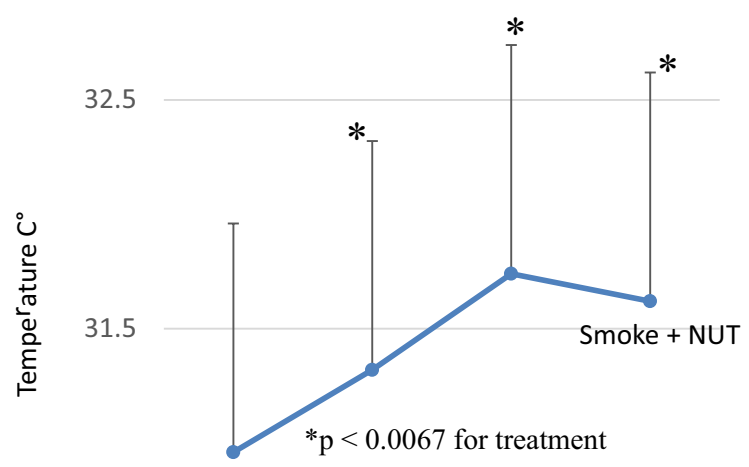

30.5
$1 \mathrm{~h}$
$2 \mathrm{~h}$
$3 h$

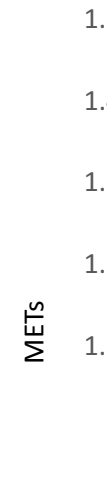

0.9

0.8
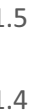

1.3

1.2
$1 \mathrm{~h}$

Time

Time

Smoke + NUT

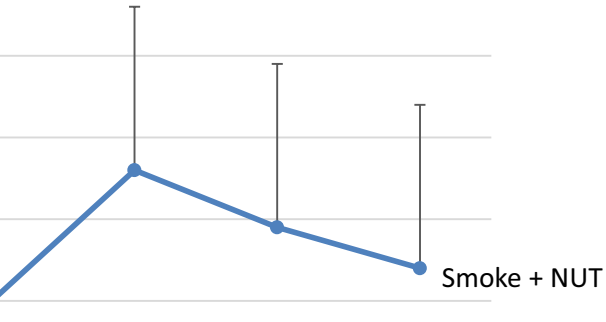

$2 \mathrm{~h}$

$3 \mathrm{~h}$

Fig. 5 Acute effects of smoking after intake of cNUT (LopiGLIK ${ }^{\circledR}$ ) on thermogenesis $(\mathbf{A})$ and energy expenditure $(\mathbf{B})$ in 14 smoker patients with hypercholesterolemia. *Different from baseline. Data are means \pm SD. Differences are considered significant when $p<0.05$ 
Fig. 6 Effects of 12 weeks consuming cNUT $\left(\right.$ LopiGLIK $^{\circledR}$ ) on total cholesterol (left) and LDL cholesterol (right) in 26 smoker and no smoker patients with hypercholesterolemia. Data are means $\pm \mathrm{SD}$, *Different from baseline. Differences are considered significant when $p<0.05$

\section{2 wks NUT combination effects on Total and LDL cholesterol}

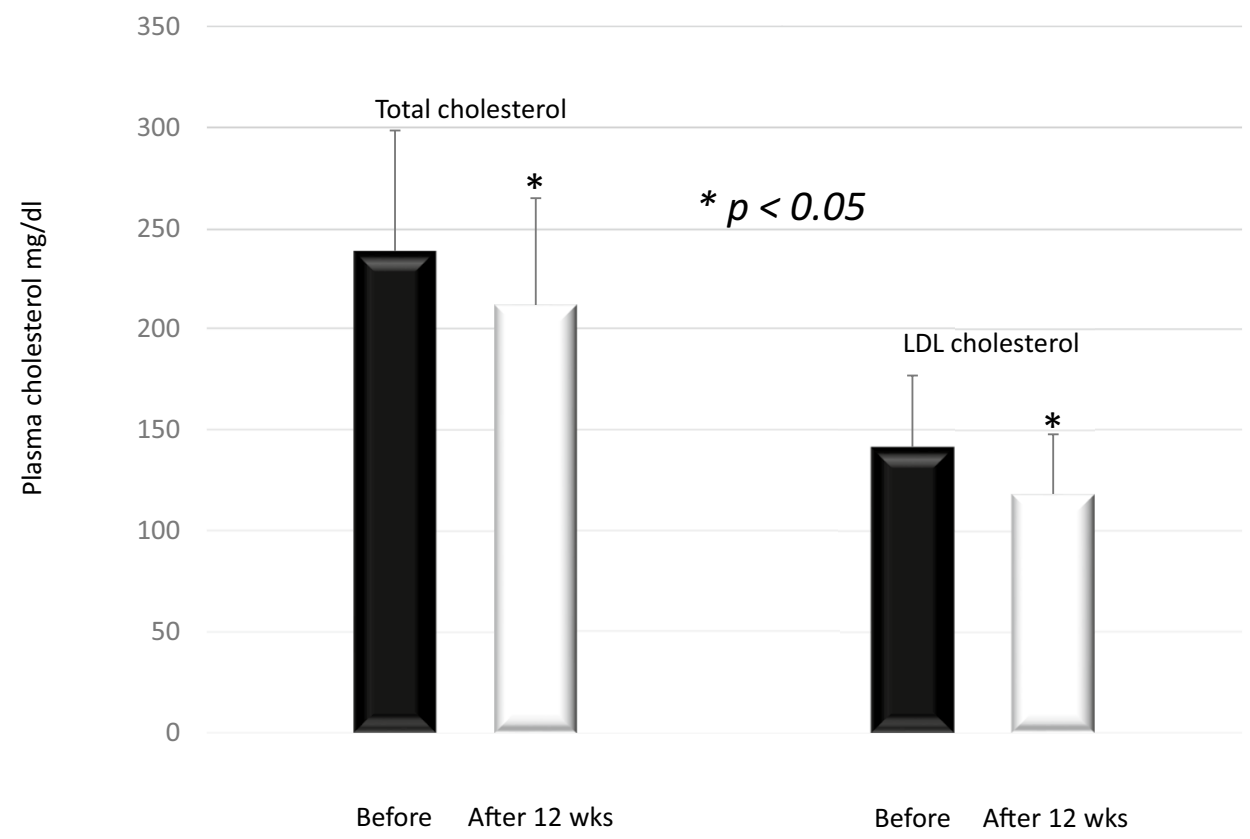

of flavonoids and anthocyanins, of great biological, pharmacological, and clinical interest because of their antioxidant and vasoactive properties [25, 26]. In line with this point, we recently observed a specific relationship between flavonoids and endothelial function [27] and also EFSA defined a claim suggesting that "a cause-and-effect relationship has been established between the consumption of cocoa flavanols and maintenance of normal endothelium-dependent vasodilation" [28]. Therefore, suggesting a specific putative role of flavonoids also included in Morus alba and in this cNUT as fundamental vasoactive compounds able to improve endothelial function and also counteracting negative effects of smoking in the population of hypercolesterolemic patients we studied. Consistent with this, our evidence on the endothelial protection obtained against cigarette smoking (a factor well known to be particularly critical in increasing cardiovascular risk and in favouring endothelial damage) [29], further supports the observations that this cNUT was also effective in improving the endothelial-dependent response derived coronary flow reserve, independently of the beneficial effects exerted on the lipid profile [30].

Moreover, of particular interest, supporting and adding valuable evidence regarding the cardiometabolic effects of this cNUT [17, 31], indeed, our results suggest a putative role of these nutraceuticals in raising thermogenesis and energy expenditure, therefore ulteriorly suggesting additional pathophysiological mechanisms involved in the effects reported on body weight and insulin resistance reduction
[17]. On this interesting point, a recent experimental study also reported that the leaf flavonoids from Morus alba were able to significantly improve skeletal muscle insulin resistance and mitochondrial function in $\mathrm{db} / \mathrm{db}$ mice modulating the AMPK-PGC- $1 \alpha$ signalling pathway (32).

\section{Conclusions}

Although our results do not clarify completely the mechanisms underlying the favourable effect of this cNUT (LopiGLIK $^{\circledR}$ ) on vascular function, BP and metabolism, and also considering the study limitations, the observations by our study suggest that an association between certain nutraceutical clinically tested together a lifestyle change could be considered a valid tool in primary prevention patients with low to moderate cardiovascular risk and in some statin intolerant patients.

\section{Limitations}

The results of this study should be interpreted considering some limitations.

In our study we considered limited number of patients, therefore our results require larger population study confirmation. Accordingly, the small sample size may account for lacking significant changes on insulin resistance and body weight reduction. 
Although our encouraging results, we provided a single blind study on acute effects that need longer and controlled larger trial to better define the clinical considered hypothesis.

Acknowledgements This research did not receive any specific grant from funding agencies in the public, commercial or not-for-profit sectors. Lopiglik was donated by Akademy-Pharma for free.

\section{Declarations}

Conflict of interest No conflict of interest exists.

Funding Open access funding provided by Università degli Studi dell'Aquila within the CRUI-CARE Agreement.

Open Access This article is licensed under a Creative Commons Attribution-NonCommercial 4.0 International License, which permits any non-commercial use, sharing, adaptation, distribution and reproduction in any medium or format, as long as you give appropriate credit to the original author(s) and the source, provide a link to the Creative Commons licence, and indicate if changes were made. The images or other third party material in this article are included in the article's Creative Commons licence, unless indicated otherwise in a credit line to the material. If material is not included in the article's Creative Commons licence and your intended use is not permitted by statutory regulation or exceeds the permitted use, you will need to obtain permission directly from the copyright holder. To view a copy of this licence, visit http://creativecommons.org/licenses/by-nc/4.0/.

\section{References}

1. Mortensen MB. Nordestgaard BG Elevated LDL cholesterol and increased risk of myocardial infarction and atherosclerotic cardiovascular disease in individuals aged $70-100$ years: a contemporary primary prevention cohort. Lancet. 2020;396(10263):1644-52.

2. Perk J, De Backer G, Gohlke H, European Association for Cardiovascular Prevention \& Rehabilitation (EACPR), ESC Committee for Practice Guidelines (CPG), et al. Eur Heart J. 2012;2012(33):1635-701.

3. Boulanger CM. Endothelium. Arterioscler Thromb Vasc Biol. 2016;36:e26-31.

4. Leung SW. Vanhoutte, PM Endothelium-dependent hyperpolarization: age, gender and blood pressure, do they matter? Acta Physiol (Oxf). 2017;219:108-23.

5. Bertoluci MC, Cé GV, da Silva AM, Wainstein MV, Boff W, Puñales M. Endothelial dysfunction as a predictor of cardiovascular disease in type 1 diabetes. World J Diabetes. 2015;6(5):679-92.

6. Grassi D, Desideri G, Ferri C. Cardiovascular risk, and endothelial dysfunction: the preferential route for atherosclerosis. Curr Pharm Biotechnol. 2011;12(9):1343-53.

7. Tangvarasittichai S. Oxidative stress, insulin resistance, dyslipidemia and type 2 diabetes mellitus. World J Diabetes. 2015;6(3):456-80.

8. Kamceva G, Arsova-Sarafinovska Z, Ruskovska T, Zdravkovska M, Kamceva-Panova L, Stikova E. Cigarette smoking and oxidative stress in patients with coronary artery disease. Open Access Maced J Med Sci. 2016;4(4):636-40.

9. Ferri C, Croce G, Cofini V, De Berardinis G, Grassi D, Casale R, Properzi G, Desideri G. C-reactive protein: interaction with the vascular endothelium and possible role in human atherosclerosis. Curr Pharm Des. 2007;13(16):1631-45.

10. Bedard K, Krause KH. The NOX family of ROS-generating NADPH oxidases: physiology and pathophysiology. Physiol Rev. 2007;87(1):245-313

11. Harvard Chan School of Public Health. The nutrition source: preventing heart disease. https://www.hsph.harvard.edu/nutritions ource/diseaseprevention/cardiovascular-disease/preventing-cvd/\#: $\sim:$ text $=$ The $\% 20$ best $\% 20$ diet $\% 20$ for $\% 20$ preventing,sodium $\% 2 \mathrm{C} \%$ 20and\%20foods\%20with\%20trans. Accessed 04 May 2021

12. Lv J, Yu C, Guo Y, Bian Z, Yang L, Chen Y, Tang X, Zhang W, Qian Y, Huang Y, Wang X, Chen J, Chen Z, Qi L, Li L, China Kadoorie Biobank Collaborative Group. Adherence to healthy lifestyle and cardiovascular diseases in the Chinese population. J Am Coll Cardiol. 2017;69(9):1116-25.

13. Grassi D, Mulder TP, Draijer R, Desideri G, Molhuizen HO, Ferri C. Black tea consumption dose-dependently improves fow-mediated dilation in healthy males. J Hypertens. 2009;27(4):774-81.

14. Grassi D, Aggio A, Onori L, Croce G, Tiberti S, Ferri C, Ferri L, Desideri G. Tea, favonoids, and nitric oxide-mediated vascular reactivity. J Nutr. 2008;138(8):1554S-S1560.

15. Tomaru M, Takano H, Osakabe N, Yasuda A, Inoue K, Yanagisawa R, Ohwatari T, Uematsu H. Dietary supplementation with cacao liquor proanthocyanidins prevents elevation of blood glucose levels in diabetic obese mice. Nutr Burbank Los Angeles County Calif. 2007;23:351-5.

16. Hironao KY, Ashida H, Yamashita Y. The cacao procyanidin extract-caused anti-hyperglycemic effect was changed by the administration timings. J Clin Biochem Nutr. 2020;67(1):61-6.

17. Trimarco V, Izzo R, Stabile E, Rozza F, Santoro M, Manzi MV, Serino F, Schiattarella GG, Esposito G, Trimarco B. Effects of a new combination of nutraceuticals with Morus alba on lipid profile, insulin sensitivity and endotelial function in dyslipidemic subjects. A cross-over, randomized, double-blind trial. High Blood Press Cardiovasc Prev. 2015;22(2):149-54.

18. Petersen KS, Flock MR, Richter CK, Mukherjea R, Slavin JL, Kris-Etherton PM. Healthy dietary patterns for preventing cardiometabolic disease: the role of plant-based foods and animal products. Curr Dev Nutr. 2017;1(12):117.

19. Daliu P, Santini A, Novellino E. From pharmaceuticals to nutraceuticals: bridging disease prevention and management. Expert Rev Clin Pharmacol. 2019;12(1):1-7.

20. Cicero AF, Borghi C. Evidence of clinically relevant efficacy for dietary supplements and nutraceuticals. Curr Hypertens Rep. 2013;15(3):260-7.

21. Cicero AFG, Grassi D, Tocci G, Galletti F, Borghi C, Ferri C. Nutrients and nutraceuticals for the management of high normal blood pressure: an evidence-based consensus document. High Blood Press Cardiovasc Prev. 2019;26(1):9-25.

22. Ghiadoni L, Faita F, Salvetti M, Cordiano C, Biggi A, Puato M, Di Monaco A, De Siati L, Volpe M, Ambrosio G, et al. Assessment of flow-mediated dilation reproducibility: a nationwide multicenter study. J Hypertens. 2012;30:1399-405.

23. Mach F, Baigent C, Catapano AL, Koskinas KC, Casula M, Badimon L, Chapman MJ, De Backer GG, Delgado V, Ference BA, Graham IM, Halliday A, Landmesser U, Mihaylova B, Pedersen TR, Riccardi G, Richter DJ, Sabatine MS, Taskinen MR, Tokgozoglu L, Wiklund O. 2019 ESC/EAS Guidelines for the management of dyslipidaemias: lipid modification to reduce cardiovascular risk. Eur Heart J. 2020;41(1):111-88.

24. Fogacci F, Grassi D, Rizzo M, Cicero AFG. Metabolic effect of berberine-silymarin association: a meta-analysis of randomized, double-blind, placebo-controlled clinical trials. Phytother Res. 2019;33(4):862-70.

25. Rodrigues EL, Marcelino G, Silva GT, Figueiredo PS, Garcez WS, Corsino J, Guimarães RCA, Freitas KC. Nutraceutical and 
medicinal potential of the morus species in metabolic dysfunctions. Int J Mol Sci. 2019;20(2):301.

26. Grassi D, Desideri G, Ferri C. Flavonoids: antioxidants against atherosclerosis. Nutrients. 2010;2(8):889-902.

27. Grassi D, Draijer R, Schalkwijk C, Desideri G, D’Angeli A, Francavilla S, Mulder T, Ferri C. Black tea increases circulating endothelial progenitor cells and improves flow mediated dilatation counteracting deleterious effects from a fat load in hypertensive patients: a randomized controlled study. Nutrients. 2016;8(11):727.

28. EFSA Panel on Dietetic Products, Nutrition and Allergies (NDA) Scientific Opinion on the modification of the authorisation of a health claim related to cocoa flavanols and maintenance of normal endothelium-dependent vasodilation pursuant to Article 13(5) of Regulation (EC) No 1924/20061 following a request in accordance with Article 19 of Regulation (EC) No 1924/2006. EFSA J 2014;12(5):3654.

29. Grassi D, Desideri G, Ferri L, Aggio A, Tiberti S, Ferri C. Oxidativestress and endothelial dysfunction: say NO to cigarette smoking. Curr Pharm Des. 2010;16(23):2539-50.
30. Esposito R, Sorrentino R, Giugliano G, Avvedimento M, Paolillo R, Santoro C, Scalamogna M, Esposito M, Ilardi F, Rozza F, Esposito G, Galderisi M, Trimarco V. Different age-independent effects of nutraceutical combinations on endothelium-mediated coronary flow reserve. Mmun Ageing. 2018;15:30.

31. Manfrin A, Trimarco V, Manzi MV, Rozza F, Izzo R. A single blind, multicenter, randomized controlled trial to evaluate the effectiveness and cost of a novel nutraceutical (LopiGLIK ${ }^{\circledR}$ ) lowering cardiovascular disease risk. Clinicoecon Outcomes Res. 2018;10:601-9.

32. Meng Q, Qi X, Fu Y, Chen Q, Cheng P, Yu X, Sun X, Wu J, Li W, Zhang Q, Li Y, Wang A, Bian H. Flavonoids extracted from mulberry (Morus alba L) leaf improve skeletal muscle mitochondrial function by activating AMPK in type 2 diabetes. $J$ Ethnopharmacol. 2020;248:112326. 